\title{
10 health stories that mattered: May 22-28
}

- New cases of cancer will increase by about $40 \%$ over the next 15 years, according to the report Canadian Cancer Statistics 2015. The projected increase will be led by surges in cases of prostate and colorectal cancer attributed to Canada's aging population. Population growth in general will also mean more cases of cancer, though incidence rates are expected to remain steady.

- The 92 eligible survivors of thalidomide in Canada have each received a tax-free payment of $\$ 125000$ to address their immediate health needs, announced Federal Health Minister Rona Ambrose. They will also receive annual tax-free payments of up to $\$ 100000$, depending on severity of disability, for the rest of their lives.

- Canada spent $\$ 28.8$ billion on prescription drugs in 2014, an increase over the previous year of $0.9 \%$, the lowest growth rate since spending was first measured in 1975, according to a report by the Canadian Institute for Health Information. Savings from increased use of generic drugs, however, is being offset by spending on new biologic drugs, such as tumour necrosis factor inhibitors, interleukin inhibitors and antineovascularization agents.

- Ontario passed the Making Healthier Choices Act, which bans flavoured tobacco products (except menthol), regulates e-cigarettes and requires large food-service chains (e.g., restaurants, grocery stores, convenience stores, etc.) to post calories for ready-to-eat items on menus and menu boards. Maximum fines have been increased for selling tobacco to youth, and it will be illegal to use e-cigarettes in nonsmoking areas and to display them in locations where they are sold.

- Quebec will not impose patient quotas on general practitioners, but the Fédération des médecins omnipraticiens du Québec must find a way to ensure $85 \%$ of the province's residents have access to a family doctor by the end of 2017. The government's initial plan, under Bill 20, to penalize family doctors who failed to meet quotas was fiercely opposed by physicians.

- Former CMA president Dr. Brian Day was elected president of Doctors of $\mathrm{BC}$, edging his closest opponent by one vote. Day, who co-owns a for-profit surgery centre in Vancouver, is a leading advocate for private health care and has launched a constitutional challenge against the province's restrictions on access to medical services outside of medicare.

- Ontario will review the clinical criteria to access an expensive medication for the rare inherited disease phenylketonuria (PKU), according to Health Minister Dr. Eric Hoskins. Patients with PKU have been pressuring the government to loosen restrictions on access to the drug sapropterin (Kuvan), which costs $\$ 70000$ a year.

- Mental health incidents will no longer be disclosed as part of police background checks on potential employees and volunteers in Toronto. Previously, the Toronto Police Service would release records of noncriminal mental health encounters such as suicide attempts, a practice opposed by mental health groups.

- The proposed cut-off age for fertility treatments in Quebec has been dropped from Bill 20, but women over age 42 who receive in vitro fertilization will not receive tax credits. Also removed from the bill is the requirement for couples seeking in vitro fertilization to first engage in three years of sexual activity.

- Multiple sclerosis shortens life expectancy by 7.5 years, according to a study by University of Manitoba researchers, published in $\mathrm{Neu}$ rology. The median lifespan of the 5797 people identified with multiple sclerosis was 75.9 years, compared to 83.4 years for 28807 people who did not have the disease. - Roger Collier, CMAJ

CMAJ 2015. DOI:10.1503/cmaj.109-5079 